\title{
عائلة القائد أحمس بن إبانا
}

\author{
وليد عبدالعال أحمد حمدان

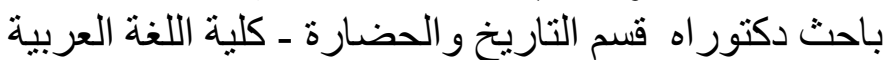 \\ جامعة الأز هر فرع أسيوط \\ Waleedabdelaa199@yahoo.com \\ ww0461055@gmail.com
}

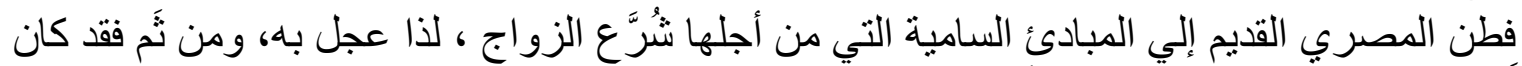

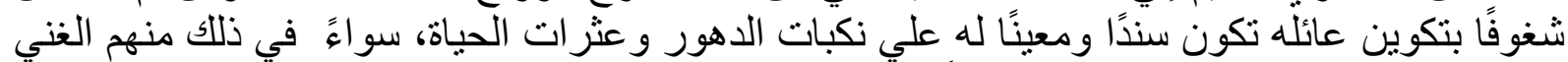

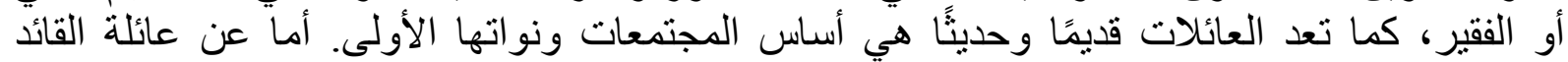

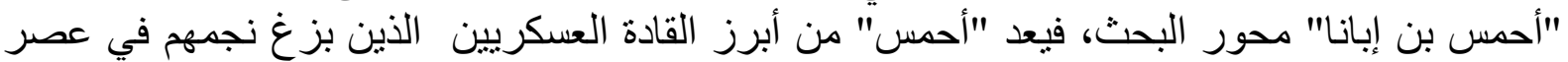

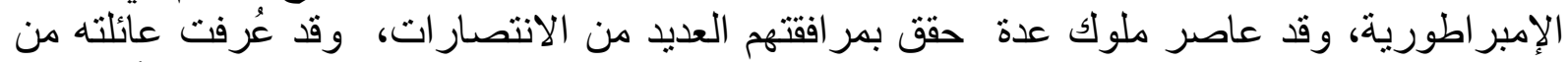

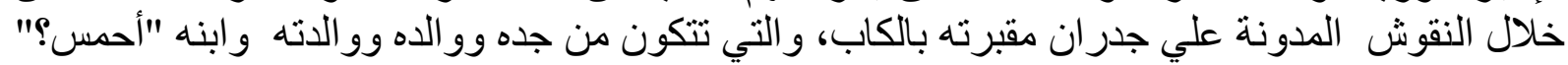

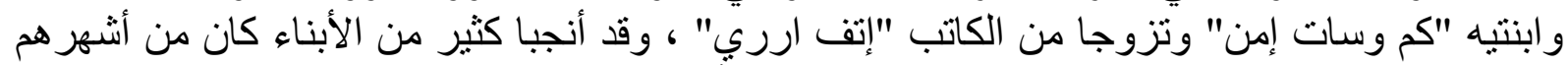

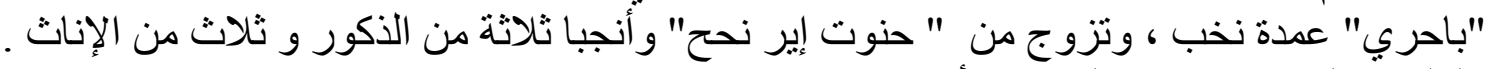

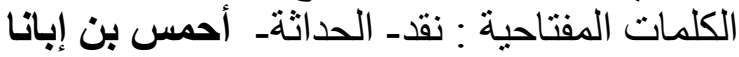

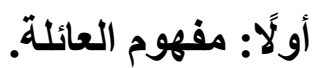

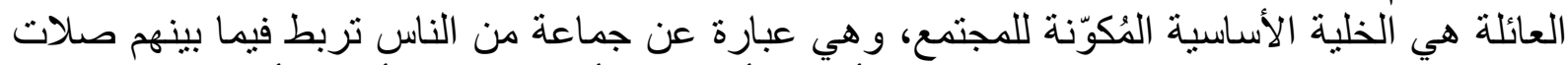
القربى المرتبطة بالعصب/ الدم و الزواج، كما أن منشأ العائلة وأساسها هما الأب والبـ والأم، وكثيرًا ما كان المصري القديم يفخر بنسبة (Assmann, 2003, 96، (Feucht, 1995, 22) ). الجمع : عائلات و عو ائل.

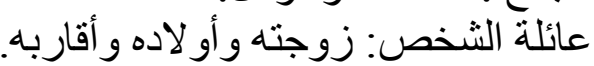

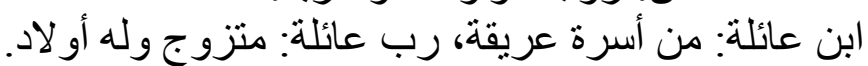

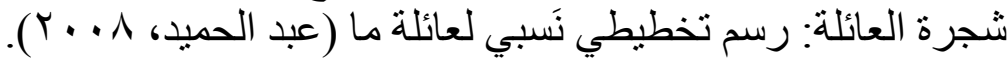

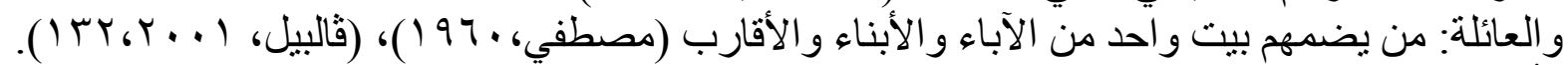

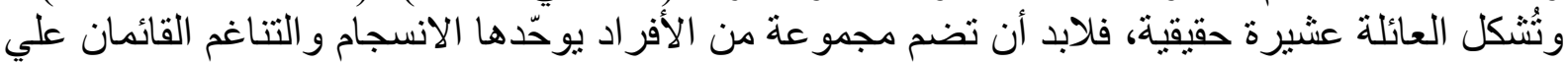

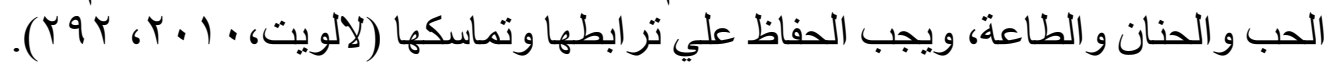

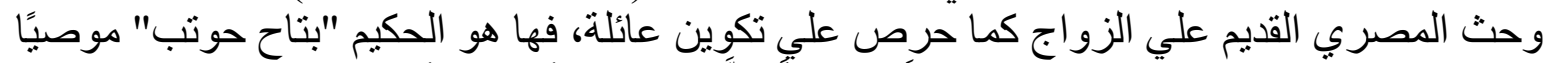

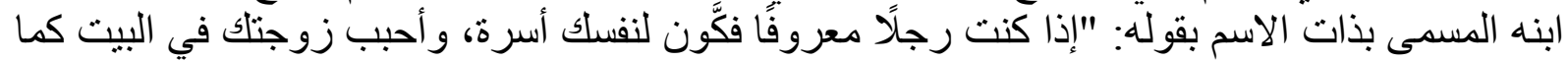

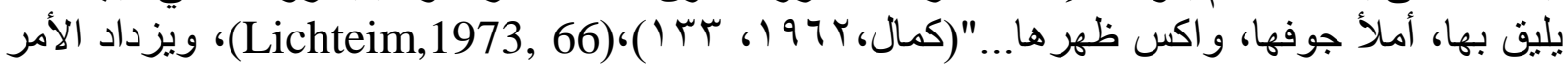

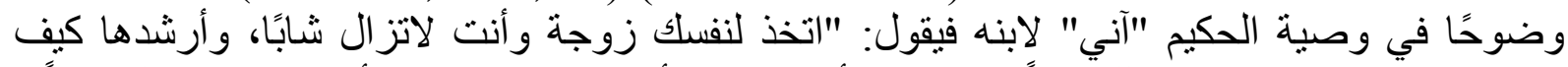

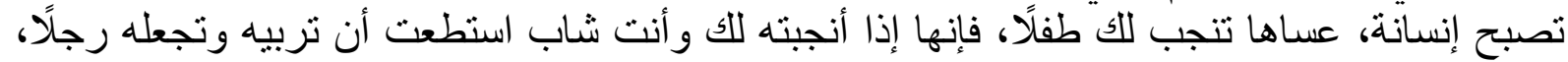

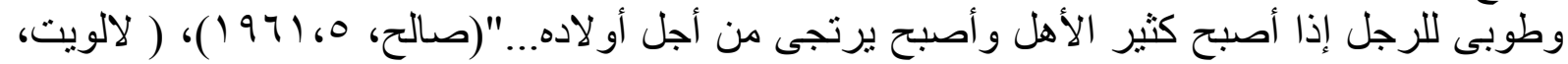
.) (19976) 1 (1)

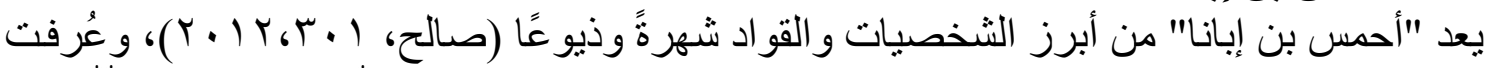

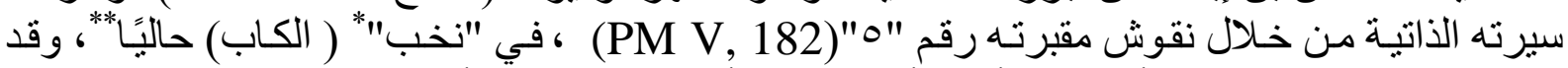

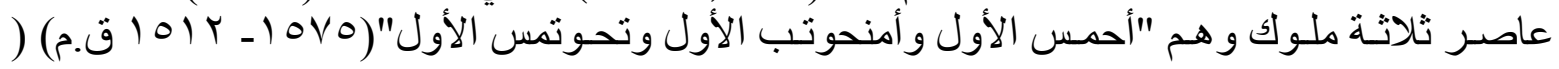


(Helck, 1975, 110)(BAR II, 3, §. 1

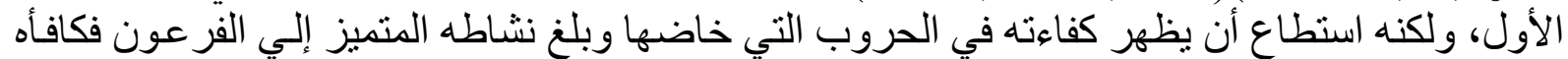

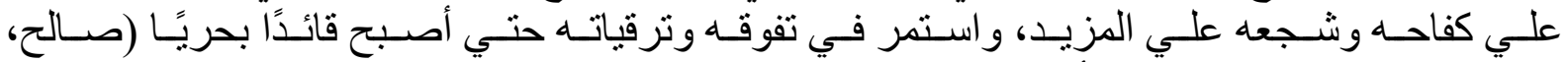

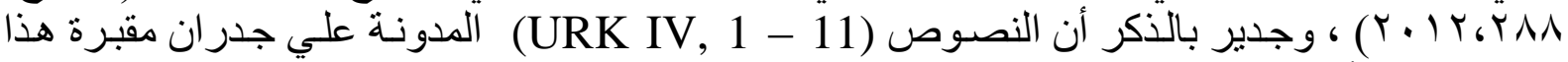

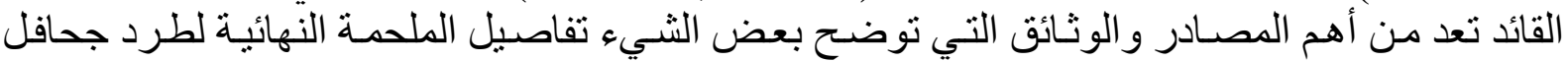

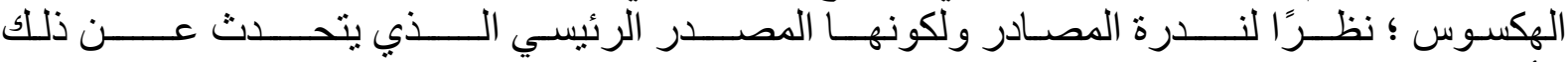

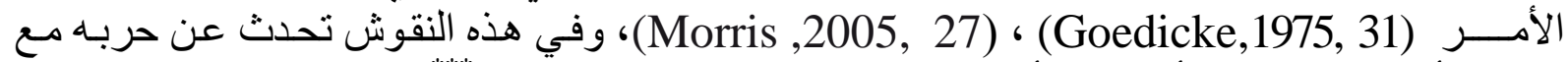

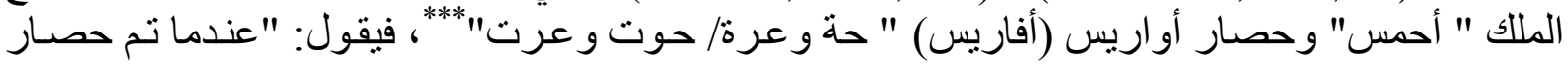

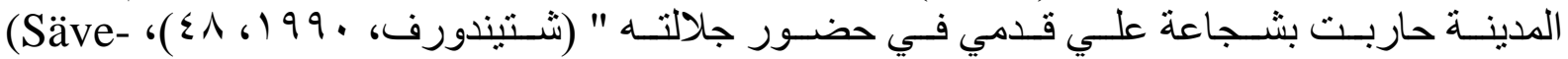

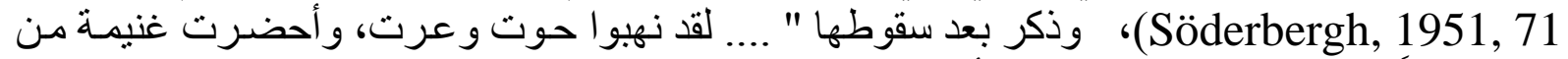

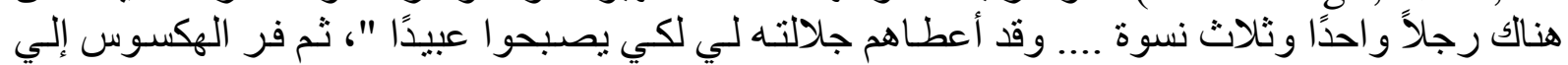

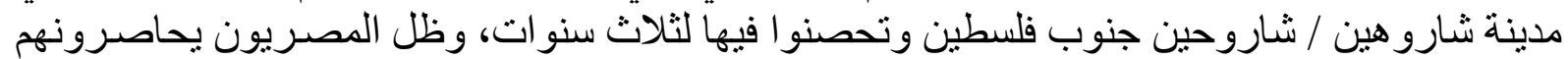

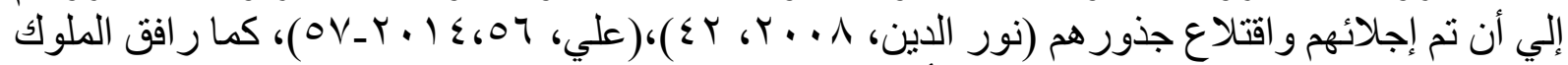

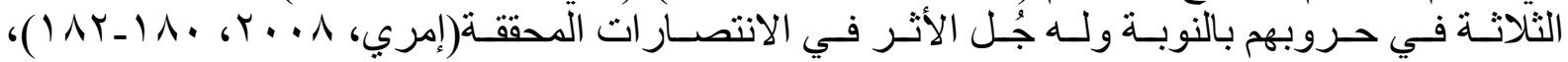

.(Brier, 2008, 260-261)، (Mertz, 2007, 135 ) ويتحدث أحمس بن إبانا عن و الده ووظيفته فيقول:

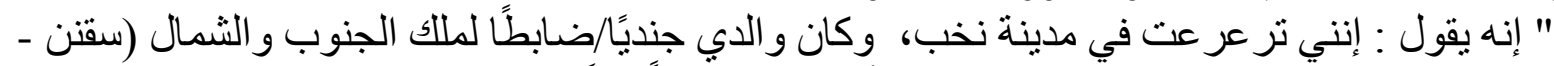

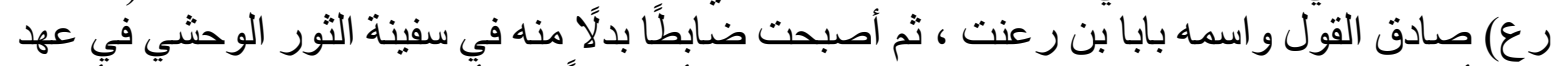

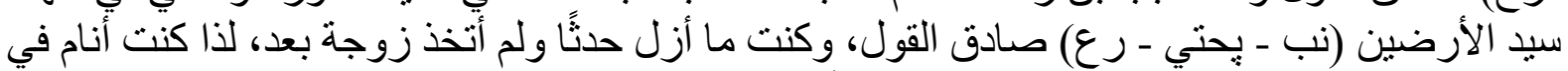

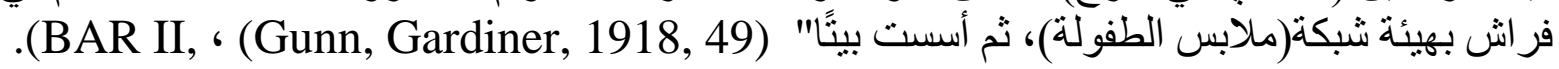
$6, \S .7)$

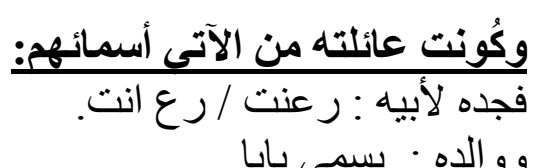

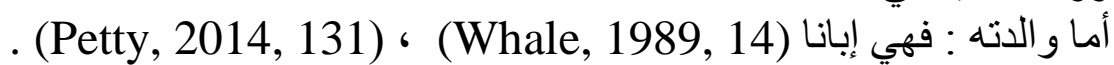
وثمة أمر جدير بالتساؤل عنده، فلماذا سُمي أحمس باسم والدانه وأثنتهر بها، علي الرغم من معرفة اسم

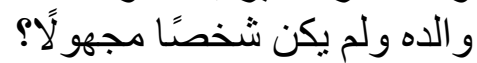

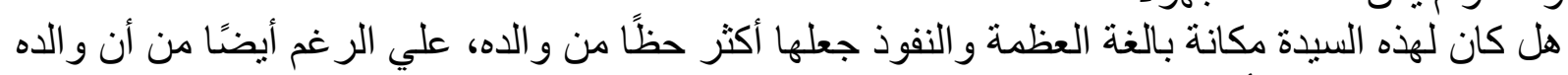

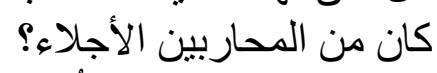
وتدعى زوجته : أبو ، وتُّلقب بسيدة الدار.

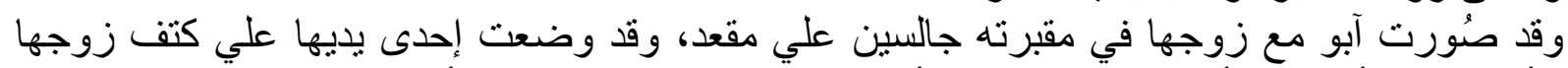

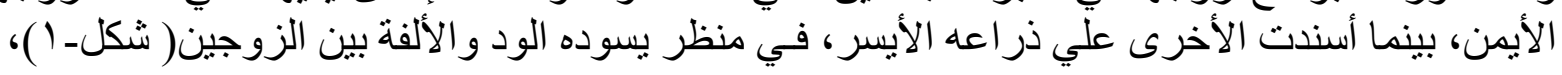

(Davies, 2009, 167, fig.8)

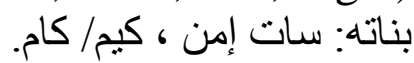
أحفاده : باحري الأول، أحمس، جحوتي ام حات،(باميو)،(سن مس)، ثوبو، نبو ام حب، سات آمون) (Davies, 2009, 151)

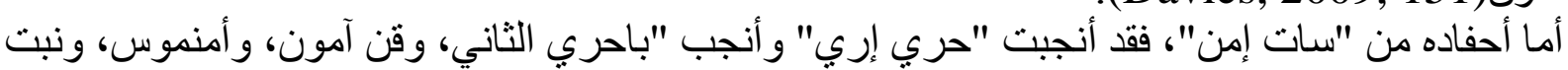

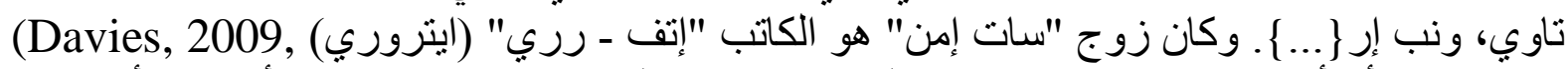

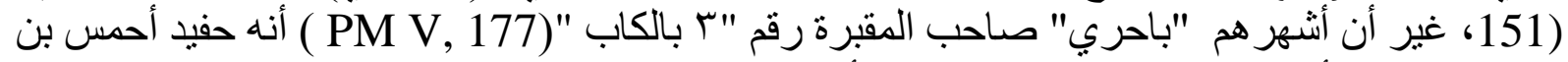

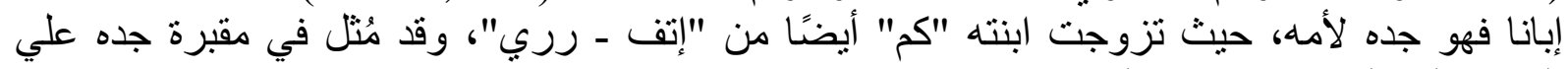

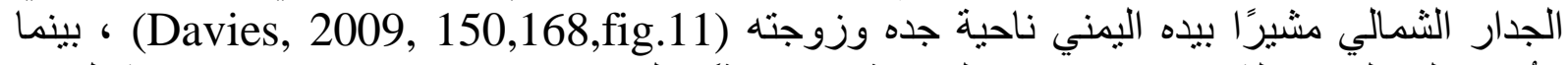

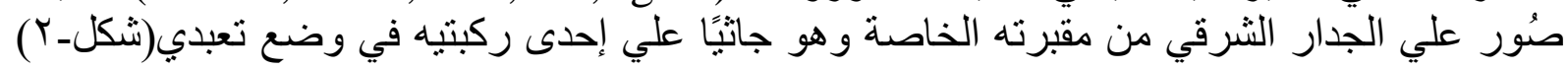




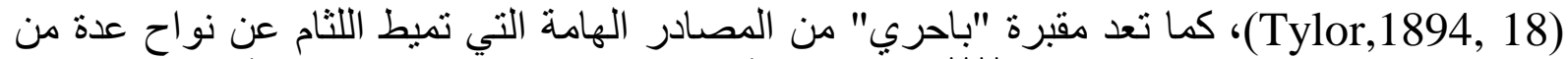

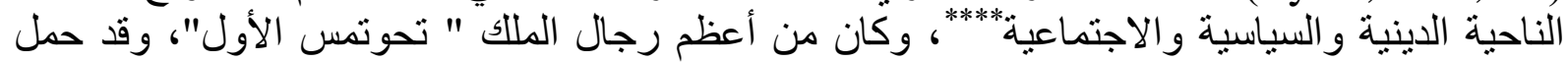

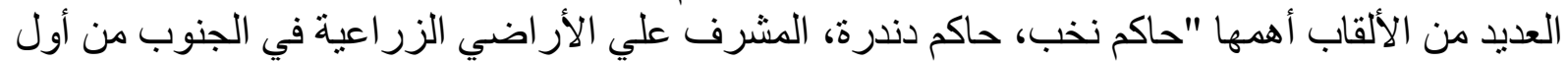

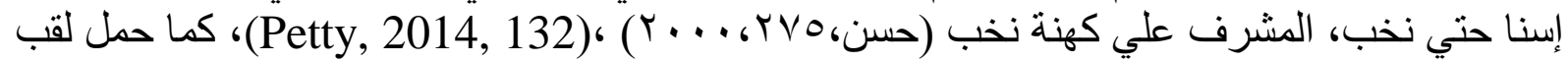

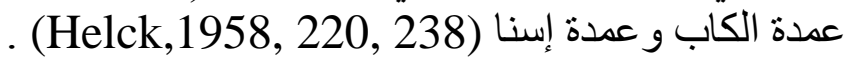

ويتفاخر عن ذاته و أعماله فيقول: الإن

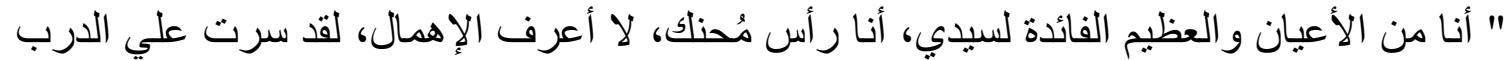

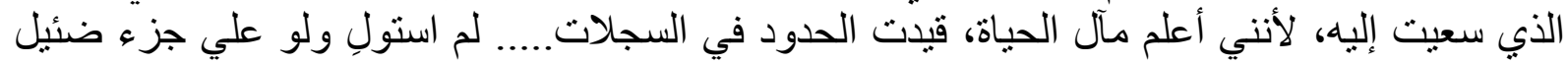

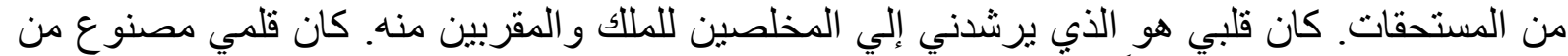

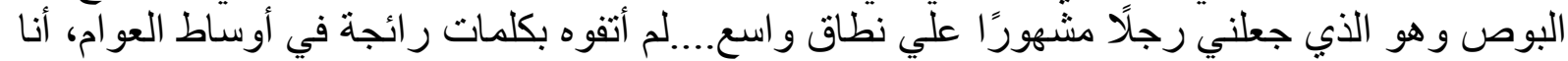

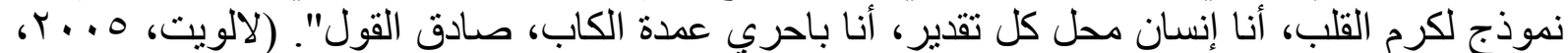

\section{ثألثًا: عائلة :- باحري عمدة نخب حفيد أحمس:

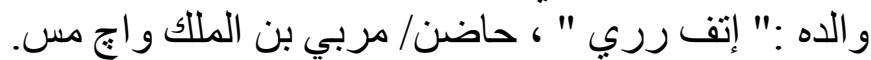

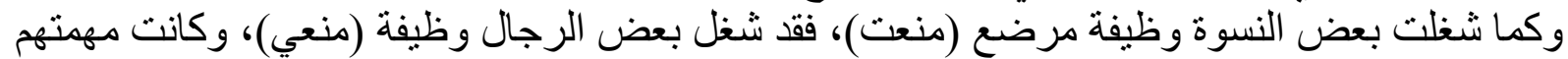

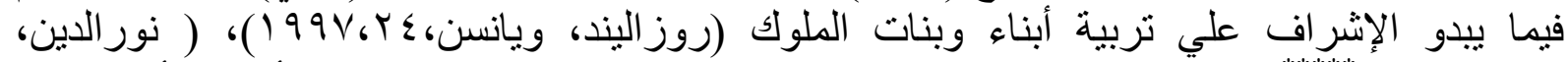

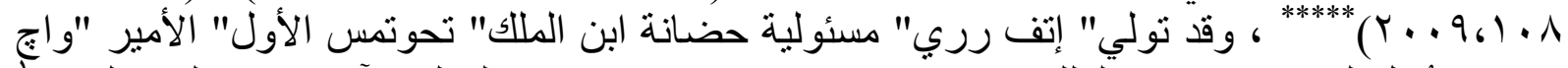

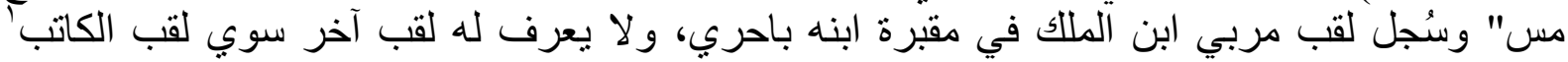

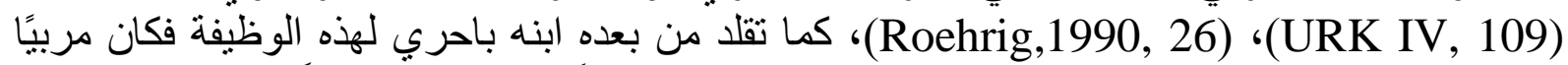

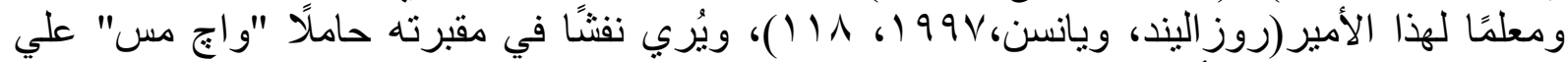

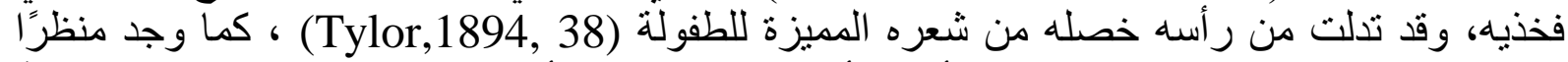

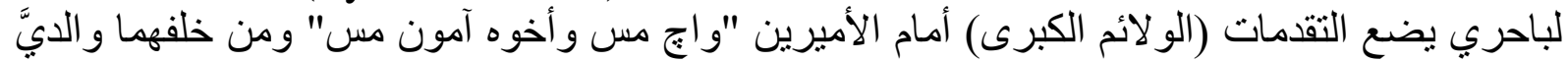
باحري (شكل-r) (Tylor,1894, 56).

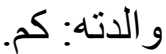

زوجته: حنوت إير نحح سبدة الدار.

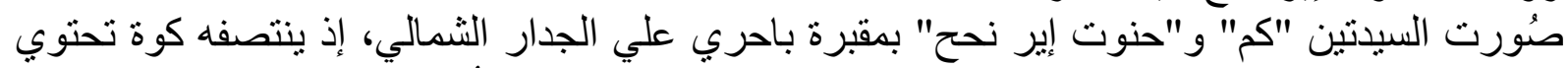

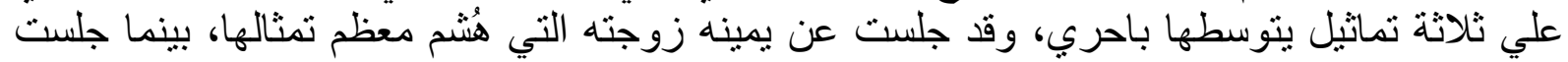

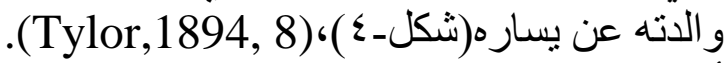

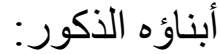

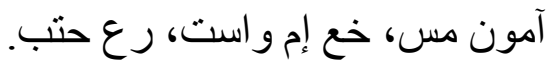

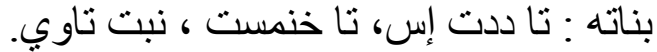

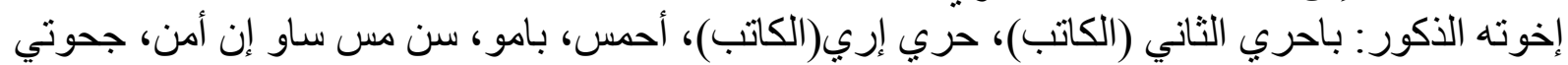

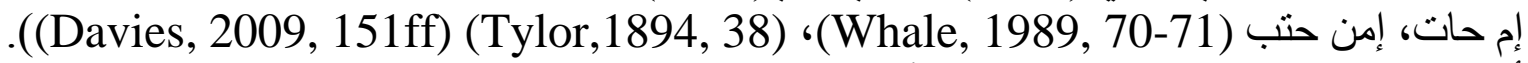

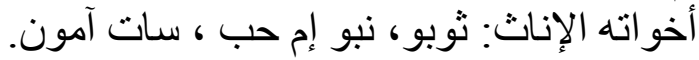

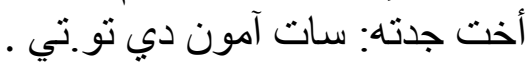

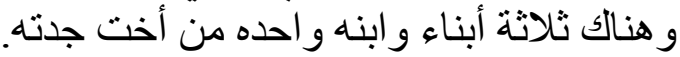

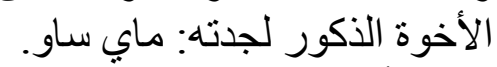

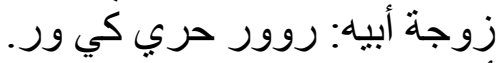

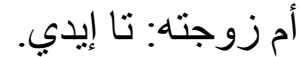
أخوات زوجته الإناث: وسرت، حنوت، تامحو. 
ابن عم زوجته: سن نفر (Whale, 1989, 70-71)، (Tylor,1894, 38)

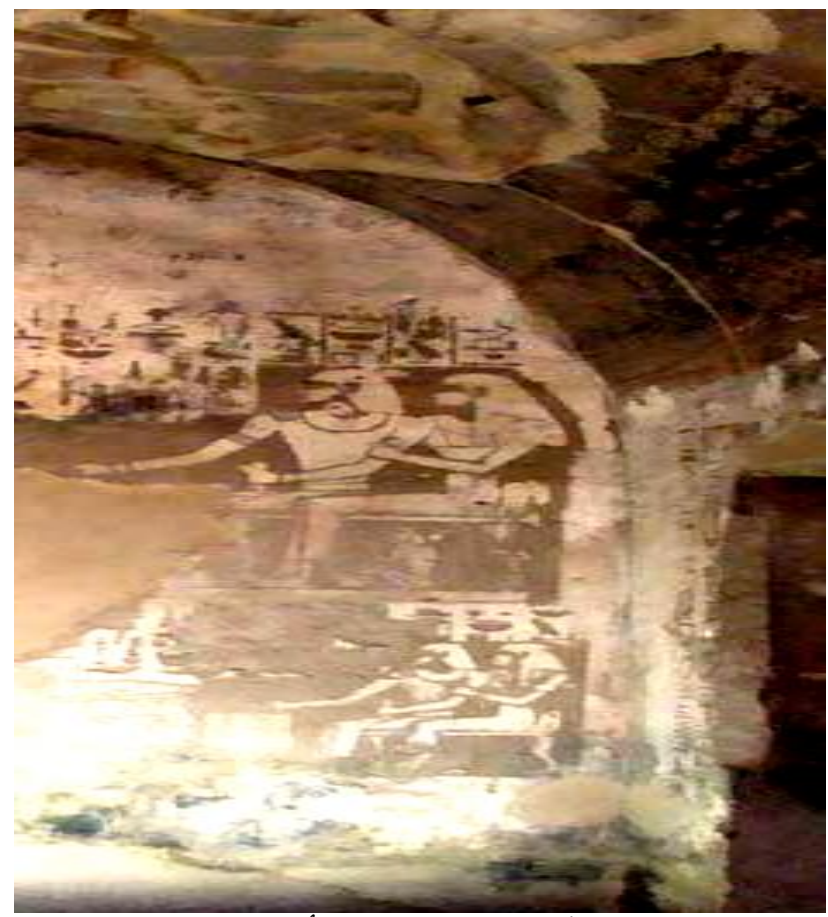

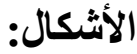

(شكل- ( ) آبو تعانق زوجها أحمس بن إبانا.

(Davies, 2009, 167,fig.8).

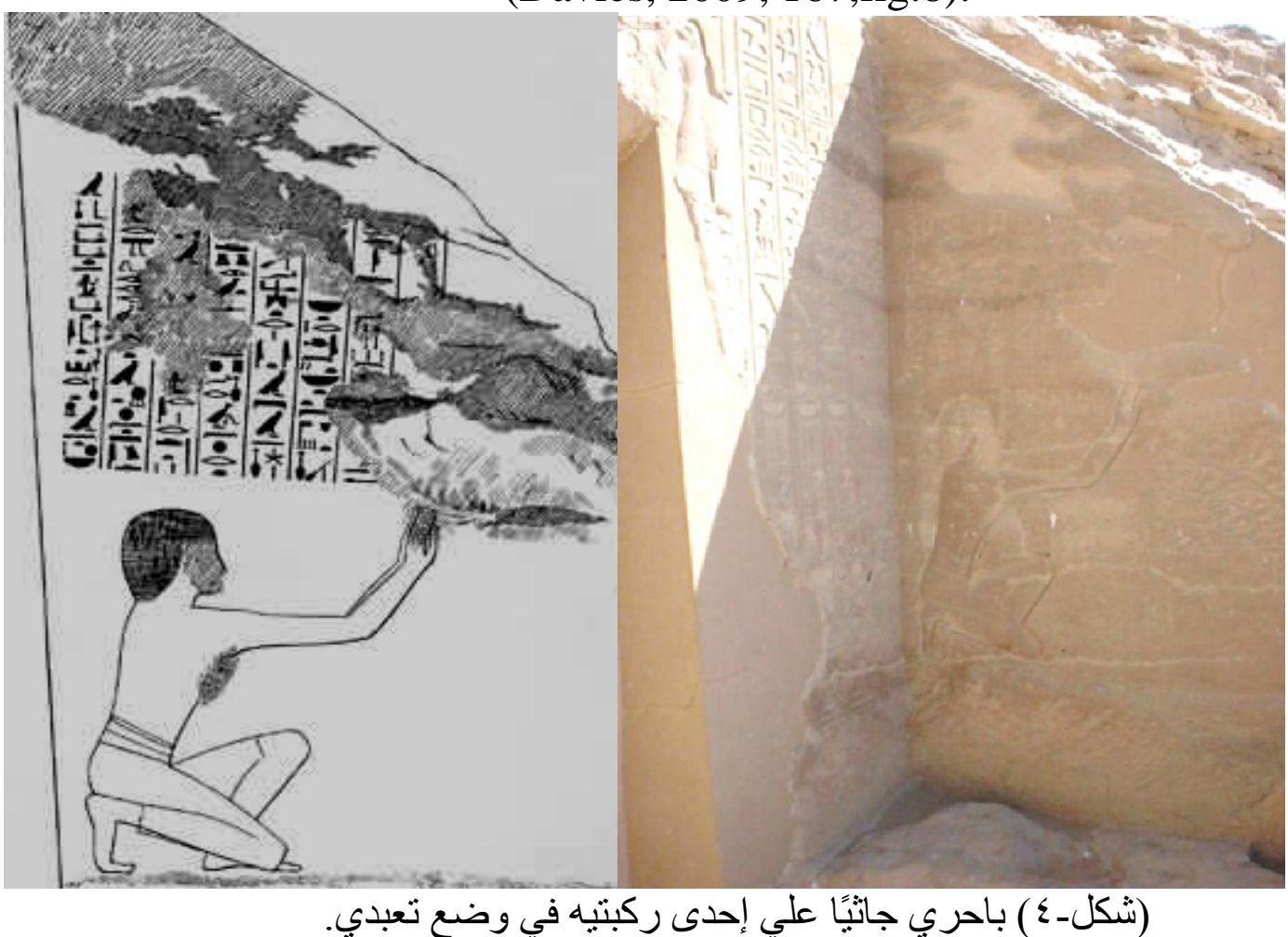

(Tylor, \& Griffth, 1894, 18). 


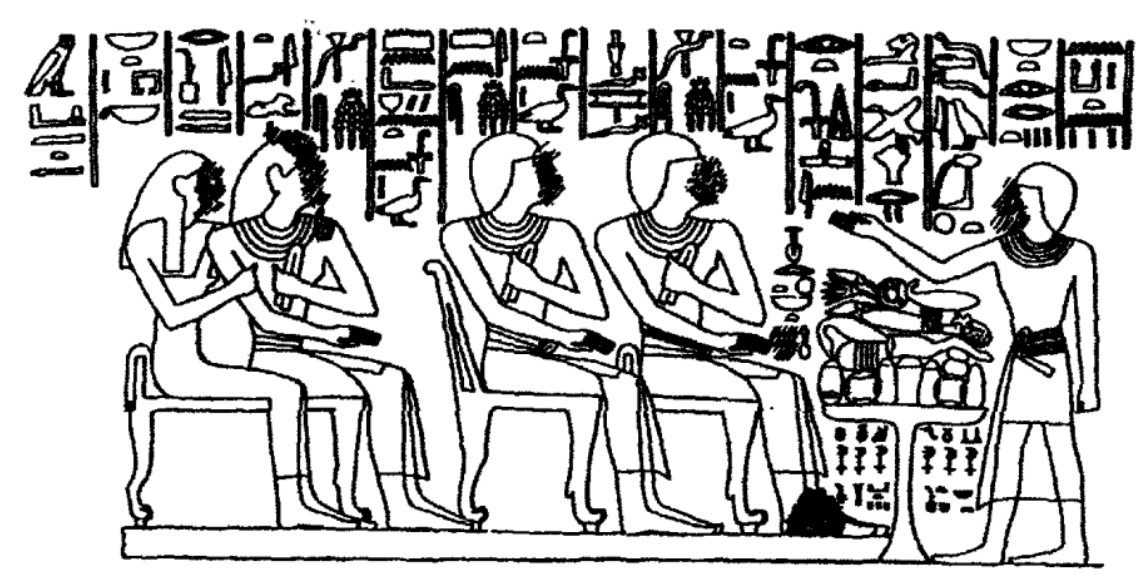

(شكل-r) باحري أمام الأميرين واج مس و أخوه ومن خلفهما والديه.

(Tylor, \& Griffth, 1894, 56).
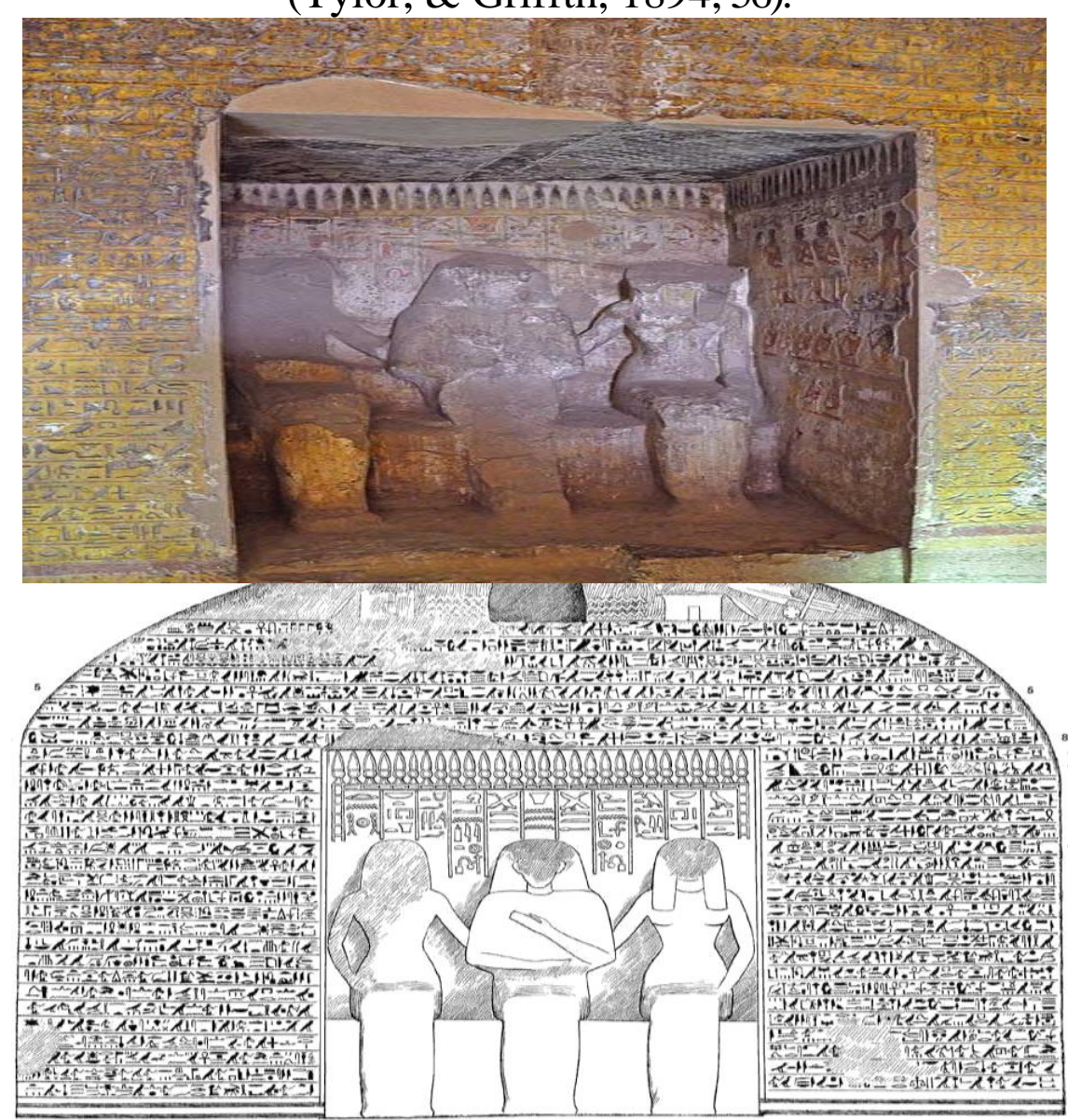

(شكل \&) ثلاثة تماثيل لباحري وو الدته وزوجتاه.

(Tylor, \& Griffth, 1894, 8). 


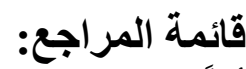

أولاً: المراجع العربية والمعابية والمعربة:

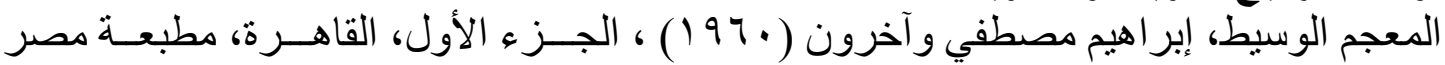

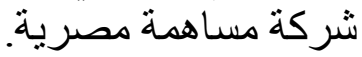

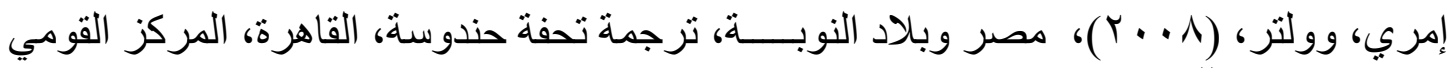

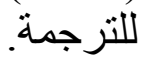

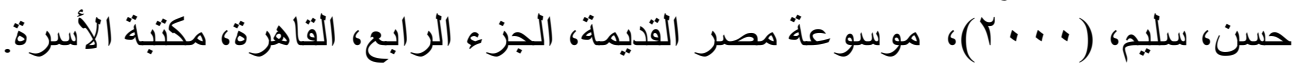

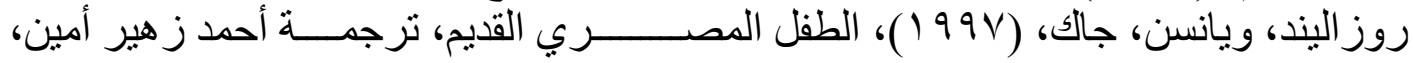

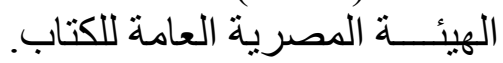

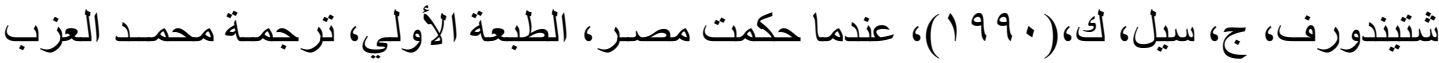

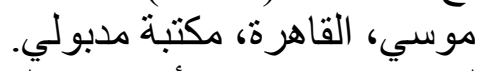

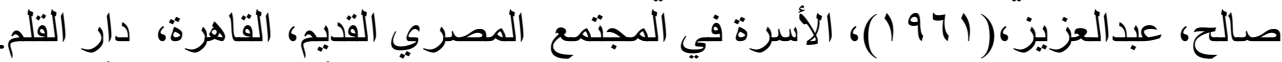

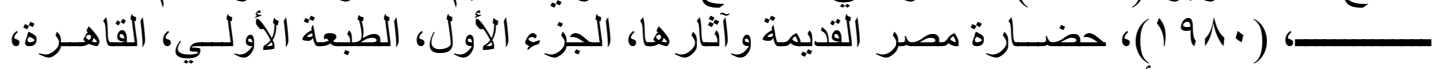

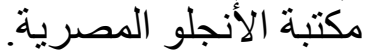

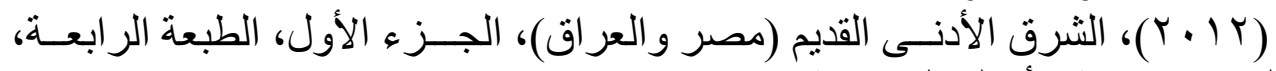

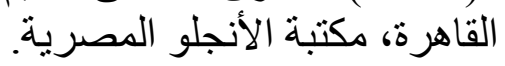

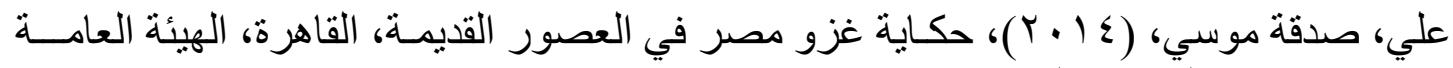
لقصور الثقافة.

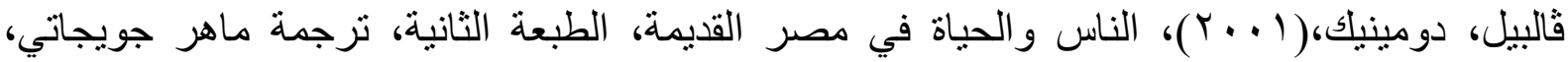
القاهرة، دار الفكر للار اسات و النشر و التوزيع.

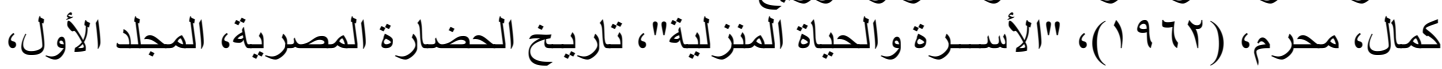

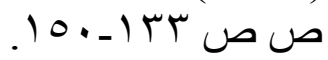

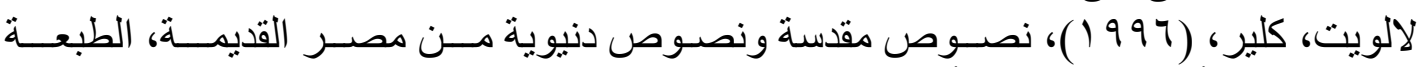

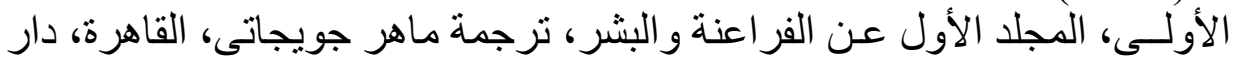

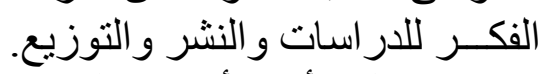

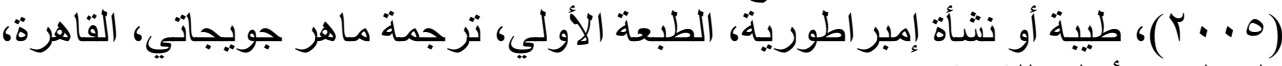

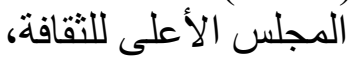

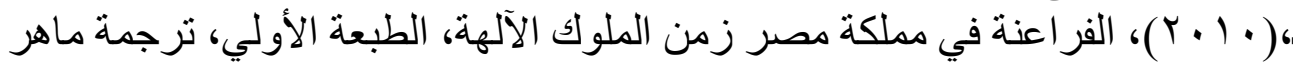

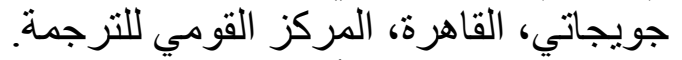

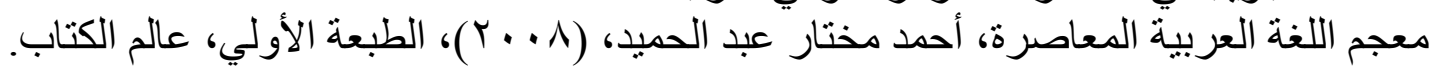

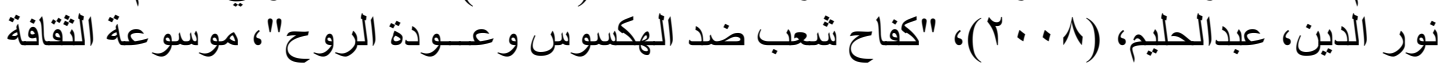

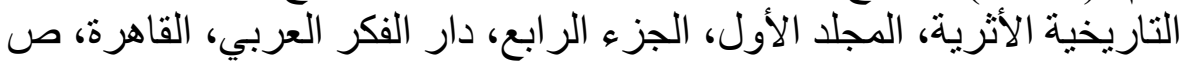

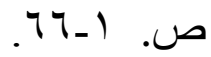

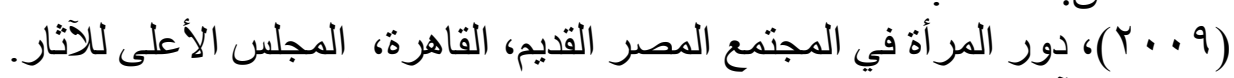

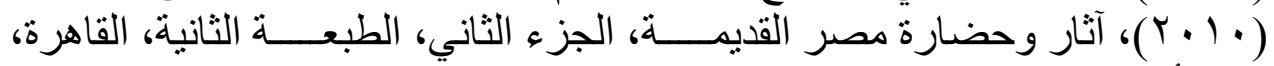

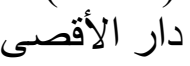

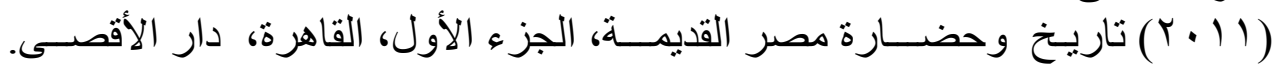




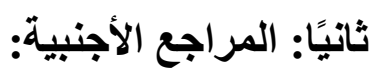

Assmann, J., (2003), Stein und Zeit Mensch und Gesellschaft im alten

Ägypten, München.

Bitak, M., (1996), Avaris "The Capital of the Hyksos, Recent Excavation at"Tell el - Dabaa", London.

Brier,B., and Hobbs, H., (2008), Daily life of the Ancient Egyptians,

London.

Davies, W.V., (2009), "The tomb of Ahmose Son-of - Ibana at Elkab,

Documenting the Family and other observations ",OLA 191,pp. 139-175.

Feucht, E., (1995), Das Kind im Alten Ägypten Die Stellung des Kindes in Familie und Gesellschaft nach altägyptischen Texten und Darstellungen, Campus Verlag Frankfurt / New York.

Goedicke, H., (1975), "Some Remarks Concerning the Inscription of Ahmose, Son of Ebana", JEA 11, pp.31-41.

, (1995), Studies about Kamose and Ahmos, Baltimore, Maryland.

Gunn, B., \& Gardiner, A., (1918), "The Expulsion of the Hyksos", JEA 5,pp. $36-56$.

Helck,W., (1958), Zur Verwaltung Des Mittleren Und Neuen Reichs, Leiden.

Lichteim, M., (1973), Ancient Egyptian Literature, vol. I: The Old and Middle Kingdom, University of California, Pares.

Mertz, B.,( 2007),Temples, Tombs \& Hieroglyphs A Popular History of Ancient Egypt, London.

Meulenaere, H.D., (1975)," EL Kab", LÄ I, Col.1226-1227.

Morris, E. F., (2005), Military Bases and the Evolution of Foreign Policy in Egypt's New Kingdom, Leiden.

Petty, B., (2014), Ahmose An Egyptian Soldier's Story, Colorado.

Raymond, W., \& Burney, E.W., (1935), "The Problem of The Site of Avaris", JEA 21, pp.10 -25.

Roehrig, C,H.,(1990), The Eighteenth Dynasty titles royal nurse (mnayt nswt), royal tutor (mnay n nswt), and foster brother/sister of Lord of the Two Lands (sn/snt mnayt nb tAwy), Ph.D., University of California at Berkeley.

Säve-Söderbergh,T., (1951), "The Hyksos Rule in Egypt", JEA 37, pp.53-71. 
Stadleman , R., (1975), "Auaris", LÄ I, Cols. 552-554.

Tylor, J., \& Griffth, F.L., (1894), The Tomb of Paheri at El Kab, London .

Whale, S., (1989), The Family in the Eighteenth Dynasty of Egypt, Sydney.

Wilson, J.A., (1955), "Buto and Hierakonpolis in the Geography of Egypt", JNES 14, pp.209-236.

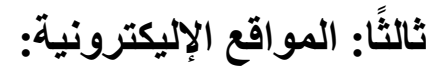

http://www.osirisnet.net/tombes/el_kab/pahery/e_pahery1.htm

"نغب: عاصمة الإقليم الثالث من أقاليم مصر العليا، والذي يمتد من هير اكونبوليس في الجنوب وحتي التئي

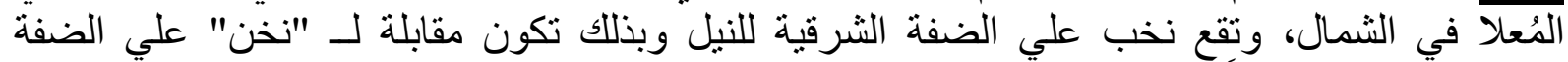

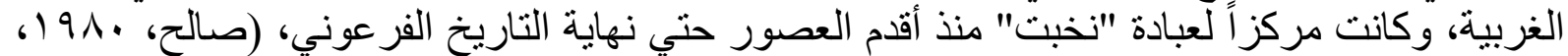
; (Y) ), r.

(Wilson, 1955, 211) ; (Meulenaere, 1975, 1226).

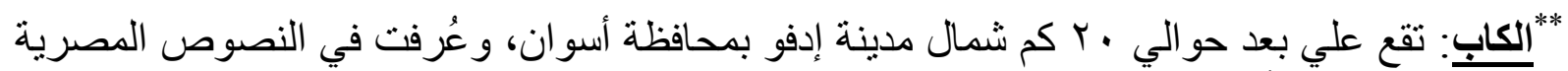

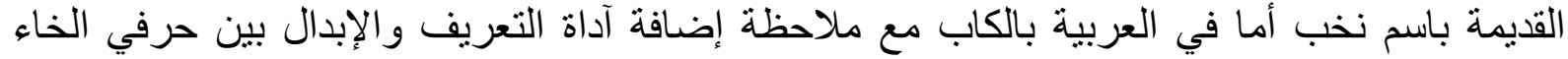
(Meulenaere 1975, 1226).

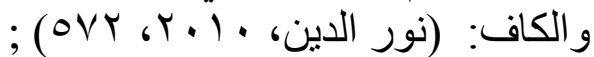

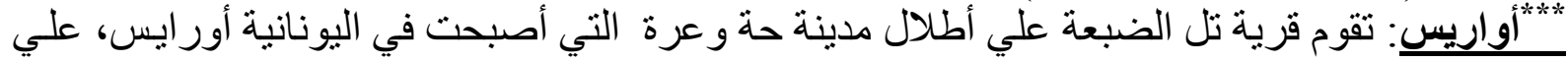

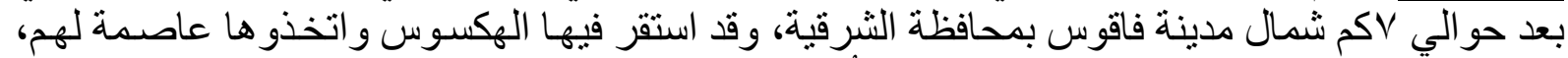

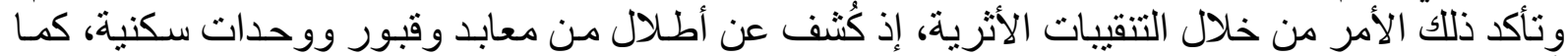

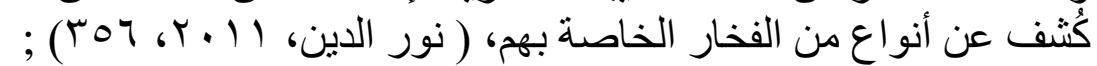
(Stadleman, 1975, 553) ; (Raymond, \& Burney, 1996, 248-250 ) ; (Morris, 2005, 27).

$$
\text { | وللمزيد عن هذه الصور راجع الموقع: }
$$
http://www.osirisnet.net/tombes/el_kab/pahery/e_pahery1.htm

$$
\text { : وللمزيد عن اللقب وحامليه راجع: }
$$

Roehrig, C,H., The Eighteenth Dynasty titles royal nurse (mnayt nswt), royal tutor (mnay n nswt), and foster brother/sister of Lord of the Two Lands (sn/snt mnayt nb tAwy), Ph.D. University of California at Berkeley,1990. 


\title{
Family Conductor Ahmos Son Ibana
}

\section{Waleed abdelaal Ahmed Hamdan}

\begin{abstract}
:
The Ancient Egyptian knews the lofty principles for which marriage was legalized, so he hastened to it, and then he was passionate about the formation of his family, which would be supportive to him for the misfortunes of the ages and the pitfalls of life, whether from them rich or poor, and families are old and modern as the basis of societies and their first years. As for the family of the leader, "Ahmose Son Ibana," the focus of the research, "Ahmose" is one of the most prominent military leaders who emerged in the era of the empire, and several kings have achieved many accompaniments to accompany them, and his family has been known through the inscriptions on the walls of his tomb in the Kab, which It consisted of his grandfather, his father, mother, and two daughters, "Km and Saat Eman". She married the first of the writer, "Itf-Arri," and they had a number of sons, the most famous of whom was "Bahri", the mayor of Nakhb.
\end{abstract}

